\title{
Cost-effective lignocellulolytic enzyme production by Trichoderma reesei on a cane molasses medium
}

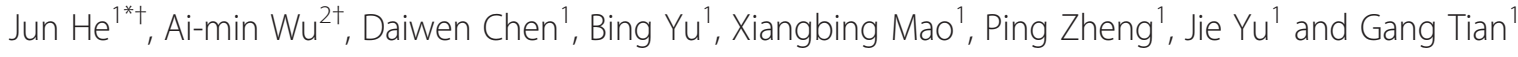

\begin{abstract}
Background: Cane molasses, an important residue of the sugar industry, have the potential as a cost-effective carbon source that could serve as nutrients for industrial enzyme-producing microorganisms, especially filamentous fungi. However, the enzyme mixtures produced in such a complex medium are poorly characterized. In this study, the secretome of Trichoderma reesei grown on a cane molasses medium (CMM) as well as on a lactose-based conventional medium (LCM) were compared and analyzed by using proteomics.

Results: In this study we show that both the CMM and LCM can serve as excellent growth media for T. reesei. The enzyme expression patterns in the two media were similar and a considerable number of the identified proteins on two-dimensional gel electrophoresis (2-DE) gels were those involved in biomass degradation. The most abundant cellulolytic enzymes identified in both media were cellobiohydrolases (Cel7A/Cel6A) and endoglucanases (Cel7A/Cel5A) and were found to be more abundant in CMM. We also found that both media can serve as an inducer of xylanolytic enzymes. The main xylanases (XYNI/XYNIV) and xyloglucanase (Cel74A) were found at higher concentrations in the CMM than LCM.
\end{abstract}

Conclusions: We analyzed the prevalent proteins secreted by T. reesei in the CMM and LCM. Here, we show that hydrolytic enzymes are cost-effective and can be produced on cane molasses as a carbon source which can be used to digest lignocellulolytic biomass.

Keywords: Enzyme, Trichoderma reesei, Cane molasses, Carbon source, Proteomics

\section{Introduction}

Lignocellulose is the most abundant renewable carbon resource on earth. It is synthesized mainly by plants and is the main constituent of plant cell walls. In recent years, more emphasis has been made to produce bioethanol from lignocelluloses derived from non-food sources and its use as an alternative to fossil fuels [1]. However, the high cost of its production remains one of the major obstacles for its cost-effective production [2,3]. Hydrolyzing enzymes (cellulase and hemicellulase) that are used to convert lignocellulosic polysaccharides to fermentable sugars contribute substantially to the cost of bioethanol production.

The filamentous fungus Trichoderma reesei is a wellknown producer of lignocellulolytic enzymes that are used for depolymerization of plant lignocellulosic biomass [4].

\footnotetext{
* Correspondence: hejun8067@163.com

${ }^{\dagger}$ Equal contributors

'Institute of Animal Nutrition, Sichuan Agricultural University, Ya'an, Sichuan 625014, People's Republic of China

Full list of author information is available at the end of the article
}

Systematic strain improvement by mutagenesis and screening has resulted in several industrial strains producing over $100 \mathrm{~g} / \mathrm{L}$ extracellular proteins, with approximately half of the secreted proteins consisting of the main cellulase, cellobiohydrolase I (Cel7a) [5].

Previous studies indicated that the production levels and enzyme systems (the relative proportions of different hydrolases) of $T$. reesei are influenced to some extent by varying the compositions of media and growth conditions [6-8]. For instance, lactose, which is a conventional carbon substrate used in industrial production media, not only promotes good growth but also strongly induces the expression of cellulase genes $[9,10]$. However, the utilization of xylose or maltose as the carbon source significantly alters the composition of the secreted enzymes by $T$. reese $i$ $[10,11]$. Cane molasses are an important residue of the sugar industry, consisting of approximately $50 \%(\mathrm{w} / \mathrm{w})$ total sugars (mainly sucrose, glucose and fructose), water, crude protein and fat, heavy metals, vitamins and other nutrients [12]. Although cane molasses with appropriate 
treatment were found to be a suitable nutrient source for a number of industrial microorganisms, including T. reesei [12-15], the enzyme mixtures produced in such media are not well characterized with respect to protein identification and quantification.

In the present study, the secretome of $T$. reesei Rut C30 (a strain already used at industrial-scale) grown on a cane molasses medium (CMM) and on a lactose-based conventional medium (LCM) was analyzed by using two-dimensional gel electrophoresis (2-DE). Proteins of interest were identified by using matrix-assisted laser desorption/ionization mass spectrometry (MALDI-MS) and electrospray ionization liquid chromatography tandem mass spectrometry (ESI-LC MS/MS). To the best of our knowledge, this is the first report on the secretome of T. reesei in CMM. Moreover, this study offers a basis for further investigation of cost-effective enzyme production using industrial residues.

\section{Results and discussion}

\section{Growth of $T$. reesei in CMM and LCM}

Before fermentation, crude molasses were diluted with distilled water to obtain $10 \%(\mathrm{w} / \mathrm{v})$ total sugar concentration and centrifuged to remove ash and other undissolved impurities. Therefore, the CMM consists of $79.8 \mathrm{~g} / \mathrm{L}$ sucrose, $11.7 \mathrm{~g} / \mathrm{L}$ glucose and $8.5 \mathrm{~g} / \mathrm{L}$ fructose. Our results show that both the CMM and LCM (containing 10\% lactose) can serve as an excellent growth medium for $T$. reesei (Figure 1A). However, the CMM yielded the highest biomass formation with $25.4 \mathrm{~g} / \mathrm{L}$, despite the fact that lactose is one of the most favored carbons by $T$. reesei $[9,10]$. The sugar concentration was recorded throughout the fermentation process and the results show that some sugars still remained unfermented in the two media when samples for secretome analysis were taken (Figure 1B). We found that both the glucose and fructose in CMM were depleted after 48 hours of fermentation. This result is in good agreement with the fact that both of the two sugars are a readily usable carbon source for microbial growth, but would act as a repressor of cellulase synthesis in $T$. reesei $[16,17]$.

\section{Enzyme production by $T$. reesei in CMM and LCM}

The production of the main lignocellulolytic enzymes by $T$. reese $i$ is transcriptionally regulated and carbon sourcedependent [18-20]. In the present study, cultivation of $T$. reesei in CMM resulted in a higher total filter paper activity (FPase) and activity on carboxymethyl cellulose (CMCase). The $\beta$-glucosidase (EC 3.2.1.21), catalyzing the hydrolysis of cellobiose to glucose, was also present at an elevated level in the CMM (Table 1). This finding is interesting considering the widespread hypothesis that the expression of the main cellulase genes in $T$. reese $i$ is antagonized by the presence of the preferred carbon sources such as the
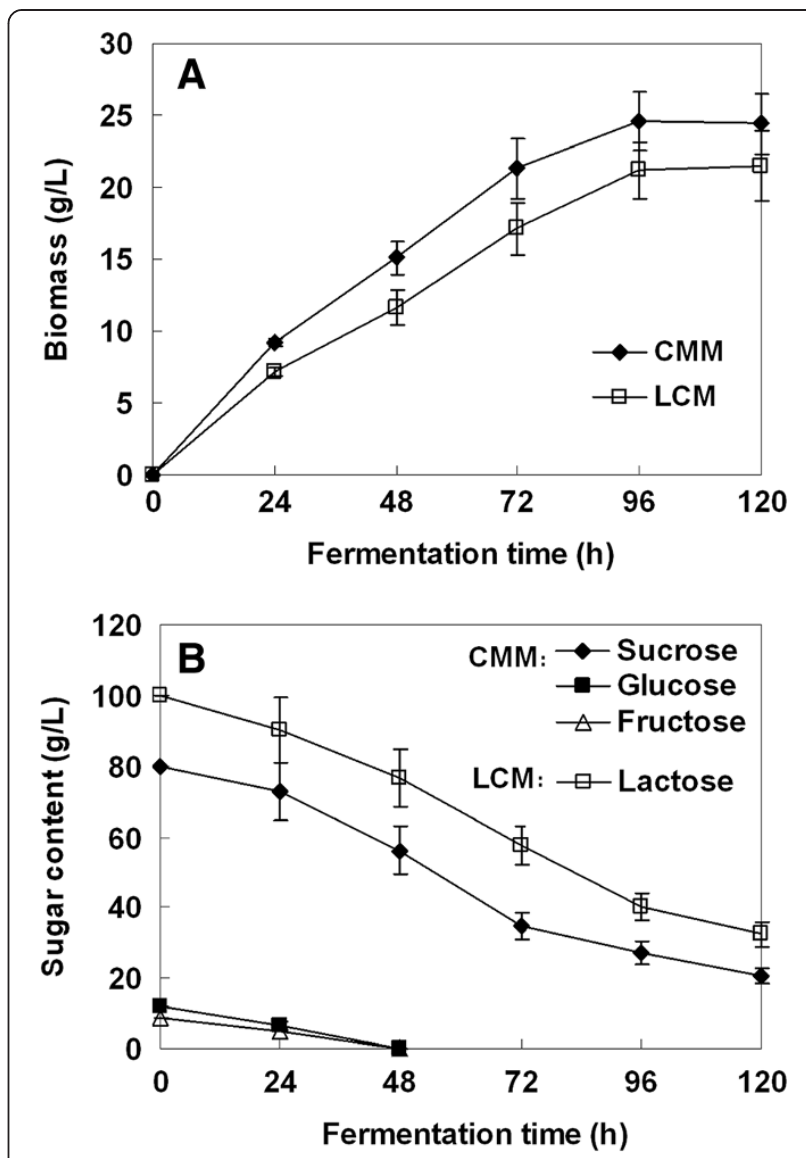

Figure 1 Biomass production and sugar consumption by $T$. reesei Rut C-30 grown on LCM and CMM. (A) Biomass production; and (B) sugar consumption. CMM, cane molasses medium; LCM, lactose-based conventional medium.

glucose and fructose in the CMM [16,17]. Our results are, however, consistent with previous reports that the cre1 deficient strain Rut C-30 used in this study does not downregulate gene expression of cellulases and hemicellulases on easily metabolized sugars [16,17]. Moreover, we found that xylanolytic enzymes were produced in both media, and the total xylanase activity produced in CMM was

Table 1 Specific enzyme activities produced by $T$. reesei in CMM and LCM

\begin{tabular}{lcc}
\hline Enzyme activity & CMM & LCM \\
\hline Biomass $^{\mathrm{a}}(\mathrm{DW} \mathrm{g} / \mathrm{L})$ & $25.4 \pm 2.09$ & $22.5 \pm 2.45$ \\
Protein content ${ }^{\mathrm{b}}(\mathrm{mg} / \mathrm{mL})$ & $4.69 \pm 0.05$ & $4.25 \pm 0.04$ \\
FPase $(\mathrm{U} / \mathrm{mg}$ protein) & $0.94 \pm 0.11$ & $0.51 \pm 0.09$ \\
CMCase (U/mg protein) & $1.15 \pm 0.21$ & $0.64 \pm 0.11$ \\
$\beta$-glucosidase (U/mg protein) & $3,948 \pm 79$ & $1,270 \pm 35$ \\
Xylanase (U/mg protein) & $36.7 \pm 4.7$ & $17.2 \pm 1.9$ \\
\hline
\end{tabular}

${ }^{a}$ Biomass production by $T$. reesei at the end of fermentation; ${ }^{b}$ protein content in the culture supernatant at the end of fermentation. CMCase, activity on carboxymethyl cellulose; CMM, cane molasses medium; FPase, filter paper activity; LCM, lactose-based conventional medium. 
$135 \%$ higher than in the LCM (172.1 versus $73.1 \mathrm{U} / \mathrm{mL})$. The higher xylanase activity observed in CMM was probably due to the presence of sucrose, since it was found to be a stronger inducer of xylanase than lactose in Thermomyces lanuginosus [21].

\section{Two-dimensional gel electrophoresis (2-DE) map of the T. reesei secretome}

Previous studies have indicated that enzymes produced by $T$. reesei are media-dependent [18-20]. The enzymes produced from different types of complex media may give completely different patterns of enzyme production. 2-DE is a powerful tool to visualize hundreds of proteins at a time, which in combination with mass spectrometry offers a way to identify them. In order to obtain the fullest complement of the hemicellulolytic enzymatic system, a lactose-based reference medium (LCM) was used, since lactose is known to induce the production of both cellulases and hemicellulases in $T$. reesei $[22,23]$. The protein maps are shown in Figure 2. We found a total of 46 distinct protein spots on the 2-D gel after staining. The distribution of the protein spots shows that most of the extracellular proteins have an isoelectric point (pI) below 6 and a molecular mass above $20 \mathrm{kDa}$. Through MALDI-MS and ESI-LC MS/MS analysis, 35 protein spots were identified as enzymes relating to the degradation of lignocellulosic biomass (Table 2). The types of identified lignocellulolytic enzymes were more than we obtained from a batch fermentation in flask [10]. The results clearly show the advantage of using $T$. reesei Rut C-30 as a most suitable microbial strain for lignocellulolytic enzyme production $[4,5]$.

We noted that the enzyme production patterns in the two growth media were qualitatively similar (Figure 2). In both media, the cellobiohydrolases Cel7 A and Cel6A were the most abundantly secreted proteins. The higher intensity of the corresponding protein spots observed on the 2-D gels was consistent with previous findings that the two proteins account for 70 to $80 \%$ of the total $T$. reesei cellulase $[24,25]$. We also identified four out of the five known endoglucanases (Cel7B, Cel5A, Cel12A and Cel61A) on the 2-D gels (Table 2). One endoglucanase (Cel45A) was not identified, which may be due in part to being produced only in a low amount and having a highly acidic pI [25]. Similar to previous reports, we only identified a $\beta$-glucosidase on 2-D gels as BGL1 $[10,26]$. This is probably due to the fact that other $\beta$-glucosidases are either intra-cellular, membrane-anchored, or play only a minor role in cellulose hydrolysis [27].

Further, some major components of the hemicellulolytic system of $T$. reesei, such as $\beta$-xylosidase (BXL1), xylanase $(\mathrm{XYN})$, xyloglucanase (Cel74A) and arabinofuranosidase (ABFI), were also identified on the 2-D gels (Table 2). Surprisingly, only two xylanases, XYNI and XYNIV, were

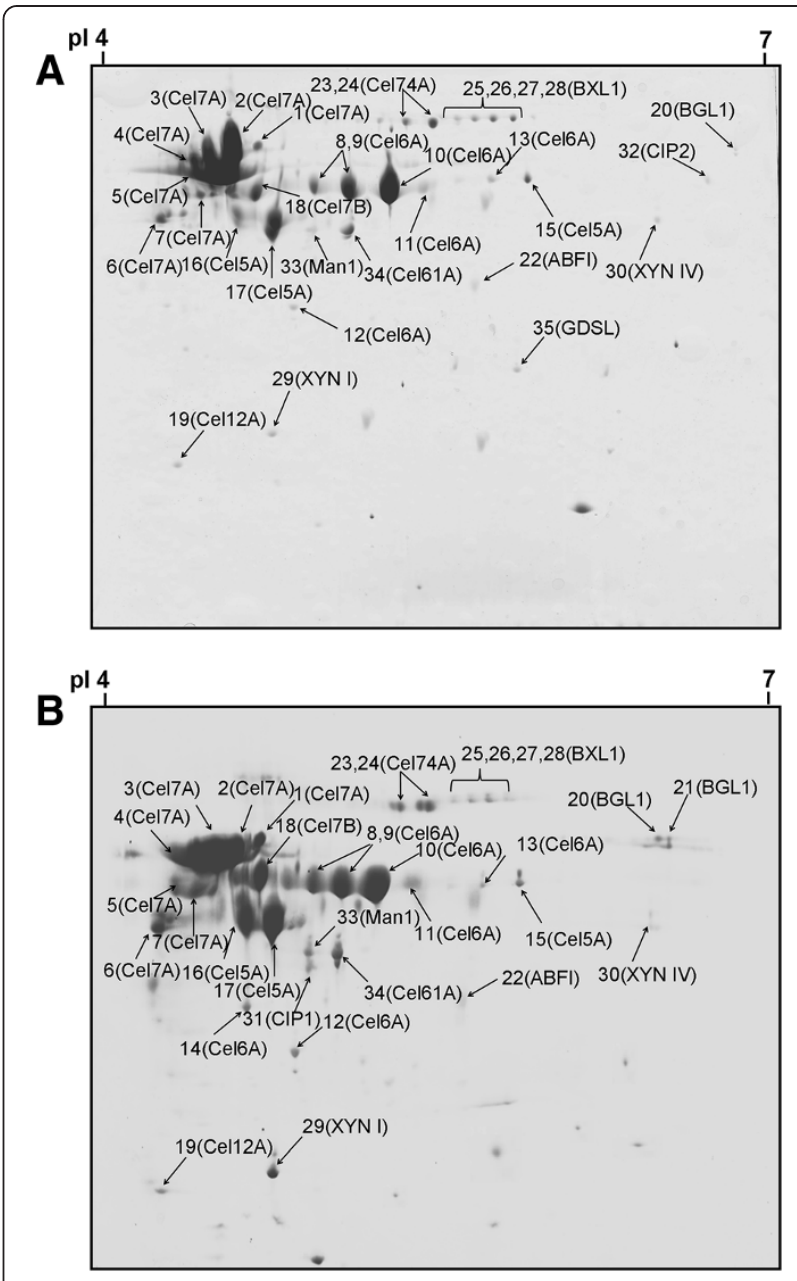

Figure 2 2-DE analysis of secreted proteins by $T$. reesei Rut C-30 grown on LCM or CMM. (A) LCM; and (B) CMM. The identified protein spots are labeled by the protein abbreviations given in the Table 2. 2-DE, two-dimensional gel electrophoresis; CMM, cane molasses medium; LCM, lactose-based conventional medium.

detected on the 2-D gels. The XYNII which has been considered as one of the major xylanases secreted by $T$. reese $i$ was not detected [28]. Moreover, the galactosidases which catalyze the hydrolysis of galactosides into monosaccharides were not identified in both media. This is also surprising, since these enzyme proteins were found to be produced in a lactose-based medium [29]. However, it may be possible that these proteins corresponded to one of the minor unidentified spots. In addition to cellulases and hemicellulases, some non-hydrolytic proteins such as CIPI and CIPII were also identified. Both these two proteins were previously characterized without a glycosyl hydrolase functional domain except for a cellulose-binding domain [19]. However, they share close relationships with cellulases and may have an important role in biomass degradation [30]. 
Table 2 Identification by MALDI-MS and ESI-LC MS/MS of proteins secreted by T. reesei Rut C-30 grown in CMM and LCM

\begin{tabular}{|c|c|c|c|c|c|c|c|}
\hline Number & ProtID ${ }^{a}$ & Protein name & Precursor mass (kDa) & $\mathrm{pl}^{\mathrm{b}}$ & Mascot score $^{c}$ & Peptides matched & Sequence coverage (\%) \\
\hline $1^{d}$ & 123989 & Cellobiohydrolase I (Cel7A) & 55.4 & 4.6 & 73 & 5 & 13 \\
\hline $2^{d}$ & 123989 & Cellobiohydrolase I (Cel7A) & 55.4 & 4.5 & 73 & 5 & 13 \\
\hline $3^{d}$ & 123989 & Cellobiohydrolase I (Cel7A) & 55.4 & 4.5 & 73 & 5 & 13 \\
\hline $4^{d}$ & 123989 & Cellobiohydrolase I (Cel7A) & 55.4 & 4.5 & 73 & 5 & 13 \\
\hline $5^{d}$ & 123989 & Cellobiohydrolase I (Cel7A) & 55.4 & 4.5 & 73 & 5 & 13 \\
\hline $6^{e}$ & 123989 & Cellobiohydrolase I (Cel7A) & 54.1 & 4.4 & 598 & 21 & 24.9 \\
\hline $7^{e}$ & 123989 & Cellobiohydrolase I (Cel7A) & 54.1 & 4.5 & 201 & 8 & 16.7 \\
\hline $8^{d}$ & 72567 & Cellobiohydrolase II (Cel6A) & 50.3 & 4.8 & 107 & 10 & 27 \\
\hline $9^{d}$ & 72567 & Cellobiohydrolase II (Cel6A) & 50.3 & 4.9 & 100 & 9 & 27 \\
\hline $10^{d}$ & 72567 & Cellobiohydrolase II (Cel6A) & 50.3 & 5.0 & 83 & 8 & 26 \\
\hline $11^{d}$ & 72567 & Cellobiohydrolase II (Cel6A) & 49.6 & 5.1 & 133 & 5 & 13.4 \\
\hline $12^{\mathrm{e}}$ & 72567 & Cellobiohydrolase II (Cel6A) & 35.1 & 4.7 & 471 & 22 & 21.4 \\
\hline $13^{e}$ & 72567 & Cellobiohydrolase II (Cel6A) & 49.6 & 5.5 & 94 & 5 & 6.6 \\
\hline $14^{e}$ & 72567 & Cellobiohydrolase II (Cel6A) & 39.2 & 4.6 & 135 & 8 & 9.2 \\
\hline $15^{d}$ & 120312 & Endoglucanase II (Cel5A) & 48.7 & 5.8 & 56 & 4 & 24 \\
\hline $16^{\mathrm{e}}$ & 120312 & Endoglucanase II (Cel5A) & 44.1 & 4.5 & 340 & 23 & 30.4 \\
\hline $17^{e}$ & 120312 & Endoglucanase II (Cel5A) & 44.1 & 4.7 & 219 & 5 & 18.4 \\
\hline $18^{e}$ & 122081 & Endoglucanase I (Cel7B) & 48.2 & 4.6 & 106 & 4 & 9.2 \\
\hline $19^{d}$ & 123232 & Endoglucanase III (Cel12A) & 25.1 & 4.5 & 83 & 8 & 32 \\
\hline $20^{d}$ & 76672 & $\beta$-Glucosidase I (BGLI) & 78.7 & 6.4 & 196 & 20 & 31.2 \\
\hline $21^{d}$ & 76672 & $\beta$-Glucosidase I (BGLI) & 78.7 & 6.5 & 106 & 17 & 23.6 \\
\hline $22^{d}$ & 123283 & Arabinofuranosidase (ABFI) & 40.2 & 5.5 & 113 & 11 & 25.1 \\
\hline $23^{d}$ & 49081 & Xyloglucanase (Cel74A) & 87.3 & 5.2 & 184 & 15 & 29 \\
\hline $24^{d}$ & 49081 & Xyloglucanase (Cel74A) & 87.3 & 5.4 & 123 & 11 & 24.7 \\
\hline $25^{\mathrm{d}}$ & 121127 & $\beta$-Xylosidase (BXLI) & 87.5 & 5.5 & 188 & 21 & 41 \\
\hline $26^{d}$ & 121127 & $\beta$-Xylosidase (BXLI) & 87.5 & 5.6 & 132 & 15 & 24.1 \\
\hline $27^{d}$ & 121127 & $\beta$-Xylosidase (BXLI) & 87.5 & 5.7 & 101 & 14 & 26.3 \\
\hline $28^{d}$ & 121127 & $\beta$-Xylosidase (BXLI) & 87.5 & 5.8 & 155 & 17 & 28.6 \\
\hline $29^{e}$ & 74223 & Xylanase I (XYNI) & 24.6 & 4.7 & 142 & 3 & 9.4 \\
\hline $30^{d}$ & 111849 & Xylanase IV (XYNIV) & 53.4 & 5.9 & 139 & 10 & 24 \\
\hline $31^{e}$ & 73638 & Cellulose-binding protein (CIPI) & 32.9 & 4.8 & 317 & 13 & 20.3 \\
\hline $32^{d}$ & 123940 & Cellulose-binding protein (CIPII) & 49.0 & 6.3 & 107 & 13 & 29 \\
\hline $33^{d}$ & 56996 & Mannanase I (MANI) & 40.1 & 4.8 & 97 & 8 & 19.2 \\
\hline $34^{d}$ & 73643 & Endoglucanase IV (Cel61A) & 40.2 & 4.9 & 86 & 2 & 6.1 \\
\hline $35^{d}$ & 121418 & Lipolytic enzyme (GDSL) & 39.3 & 5.7 & 113 & 11 & 34 \\
\hline
\end{tabular}

${ }^{a}$ From The Genome Portal of the Department of Energy Joint Genome Institute (JGI) for T. reesei; ${ }^{b}$ pl determined by 2 -DE; ${ }^{\text {Canalyzed by }}{ }^{\mathrm{d}} \mathrm{MALDI}-\mathrm{MS}$ or ${ }^{\mathrm{e}} \mathrm{ESI}-\mathrm{LC}$ MS/ MS. 2-DE, two-dimensional gel electrophoresis; CMM, cane molasses medium; ESI-LC MS/MS, electrospray ionization liquid chromatography tandem mass spectrometry; LCM, lactose-based conventional medium; MALDI-MS, matrix-assisted laser desorption/ionization mass spectrometry.

\section{Quantification and comparison of the extracellular} protein produced by $T$. reesei

The relative amount for each protein spot (percentage of total spots volume) was quantified using ImageMaster II software (GE Healthcare, Uppsala, Sweden). The spot numbers detected on the two protein maps were similar. However, T. reesei secreted more enzyme proteins into the CMM than LCM. It is a well-known fact that $T$. reese $i$ is an efficient producer of cellulolytic enzymes, and expresses two cellobiohydrolases (Cel7A and Cel6A), enzymes that catalyze the release of cellobiose from the reducing or nonreducing end of cellulose, and five endoglucanases (Cel7B, Cel5A, Cel12A, Cel61A and Cel45A), enzymes that attack cellulose in an endo-acting manner [31]. Our protein spot quantification indicated that $T$. reesei produced $9.7 \%$ more total cellobiohydrolase $($ Cel7A + Cel6A) in the CMM than 
LCM (Figure 3A). This is due to a significantly higher Cel6A level produced in the CMM (34.5\% in CMM versus $18.1 \%$ in LCM). As a result, the ratio of Cel7A to Cel6A was much higher in the LCM than CMM (Figure 3B). This finding is surprising since the expression of Cel7A and Cel6A was considered to be co-regulated [32]. Similarly, the relative amount of total identified endoglucanases $($ Cel7B + Cel5A + Cel12A + Cel61A) produced was also higher in CMM (Figure 3C). These results are, however, not only consistent with the carbon-dependent nature of the cellulolytic system in $T$. reesei, but also suggest that the sugars present in the CMM (sucrose) may be more efficient than lactose as an inducer for the main cellulolytic enzymes.

Complete degradation of cellulosic materials requires an exocellulase with specificity for a variety of $\beta$-Dglycoside substrates [33]. $\beta$-Glucosidase (EC 3.2.1.21), catalyzing the hydrolysis of terminal non-reducing residues in $\beta$-D-glucosides with release of glucose, are usually induced by specific substrates such as lactose [10]. Other carbon substrates, such as xylose, arabinose and sophorose (one of the most potent inducers of T. reese $i$ cellulases), do not induce $\beta$-glucosidase (BGL1) and, in high concentrations, even repress its formation [10,34]. In the present study, the enzyme was induced in both media, and the total amount of BGL1 produced in the CMM was 4.5-fold higher than that in the LCM (Figure 3D). Previous studies have indicated that BGL1 may be involved in the formation of cellulase inducers $[27,35]$. Therefore, the elevated total cellulase activity in the CMM may result from a higher BGL1 level produced in this medium.

T. reesei is also found to be an efficient producer of hemicellulases. The relative amount of $\beta$-xylosidase (BXL1) required for complete degradation of xylan to xylose was higher in the LCM than in CMM (Figure 3E). The result is consistent with a previous report that lactose is a stronger BXL1 inducer than sucrose and fructose in Cellulomonas flavigena [36]. Moreover, the glucose in the CMM was, however, considered as a non-inducing sugar [36,37]. No significant difference was observed with respect to the level of Cel74A and XYNIV in the two growth media. However, both the level of XYNI and the total xylanase (XYNI + XYNIV) were found at elevated levels in the CMM (Figure 3E). The other two T. reesei xylanases (XYNII and XYNIII) were not detected, which could be because they were produced in lower amounts and have
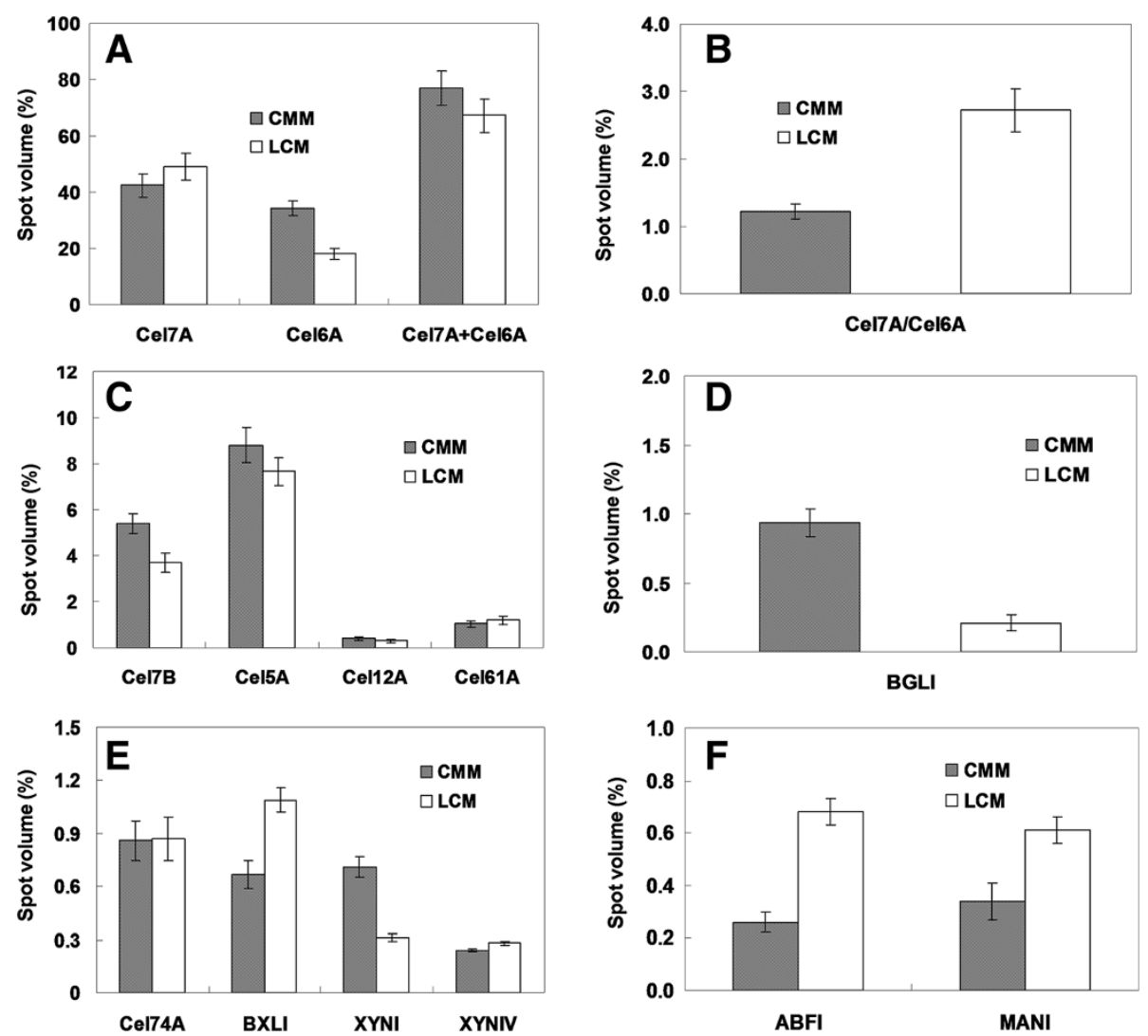

Figure 3 Comparative analysis of the secretome of T. reesei Rut C-30 grown on LCM or on CMM. (A) Relative abundance of Cel7A and Cel6A; (B) Cel7A to Cel6A ratio; (C) relative abundance of Cel7B, Cel5A, Cel12A and Cel61A; (D) relative abundance of $\beta$-glucosidase; and $(\mathbf{E}, \mathbf{F})$ relative abundance of other identified hemicellulolytic enzymes. CMM, cane molasses medium; LCM, lactose-based conventional medium. 
a basic pI (the predicted pI of XYNII is 7.9) that is out of the $\mathrm{pH}$ range $(\mathrm{pH} 4$ to 7$)$ used in the 2-DE analysis. We also cannot rule out the possibility that they have a higher level of degradation in the two media $[10,26]$. The relative amount of other identified hemicellulases, such as the arabinofuranosidase (ABFI) and mannanase (MANI), also showed marked differences. However, these two enzymes were produced only in small amounts (Figure 3F).

While the results reported were reproducibly obtained on all 2-D gels analyzed, it should be noted that some spots might have contained co-migrating proteins that were not detected in the MALDI-MS analysis. These proteins would have affected the relative quantification of the identified proteins. As MALDI-MS identifies the prevalent proteins that are present in a gel sample, these errors are, however, considered to be negligible. Moreover, it is noteworthy that the relative amount (spot volume) for identified enzyme proteins fit well with data obtained from specific enzyme activity (Table 1). The higher FPase and CMCase in the CMM can be related to the higher amounts of cellobiohydrolases (Cel7A + Cel6A) and endoglucanases $($ Cel7B + Cel5A + Cel12A + Cel61A $)$ in this medium. Similarly, the higher $\beta$-glucosidase and xylanase-specific activities are consistent with the higher amounts of BGL1 and total xylanases (XYNI + XYNIV) produced in the CMM.

\section{Conclusion}

Both the CMM and LCM can serve as an excellent growth medium for $T$. reesei. As compared to the LCM, $T$. reesei produces a considerable number of cellulases in the CMM and also higher levels of xylanases. Importantly, this study not only shows the prevalent proteins secreted by $T$. reesei in the CMM and LCM, but the results also suggest that production of hydrolytic enzymes using cost-effective carbon sources, such as components in cane molasses, deserves more attention in the future.

\section{Methods}

\section{Pretreatment of cane molasses}

Cane molasses were obtained from Meishan sugar refinery (Sichuan, People's Republic of China). It contained 27\% $(\mathrm{w} / \mathrm{w})$ water, 37.5\% (w/w) sucrose, 9.5\% (w/w) reduced sugars (glucose and fructose), $2.5 \%(\mathrm{w} / \mathrm{w})$ other carbohydrates, $4.5 \%(\mathrm{w} / \mathrm{w})$ crude protein, $0.1 \%(\mathrm{w} / \mathrm{w})$ crude fat, $8.3 \%(\mathrm{w} / \mathrm{w})$ ash, $4.1 \%(\mathrm{w} / \mathrm{w})$ salt and $6.5 \%(\mathrm{w} / \mathrm{w})$ metal ions, such as calcium, potassium, sodium, iron, magnesium, copper, and so on. The crude molasses were diluted with distilled water to obtain $10 \%(\mathrm{w} / \mathrm{v})$ total sugar concentration and centrifuged to remove ash and other undissolved impurities. This molasses solution was used for the pretreatment of cation exchange resin (to remove metal ions) as described by Roukas [38].

\section{Fermentation in multi-bioreactor}

Batch cultivations were carried out in a bioreactor (Runze Biotech Co. Ltd., Nanjing, People's Republic of China) using T. reesei Rut C-30. Six $500 \mathrm{~mL}$ bioreactor vessels (three vessels per group) equipped with condensers, FermProbe $\mathrm{pH}$ electrodes and dissolved oxygen sensors $\left(\mathrm{pO}_{2}\right.$ electrodes) were autoclave-sterilized and filled with $250 \mathrm{~mL}$ pretreated cane molasses (CMM) or a reference medium (with $10 \%$ lactose as the carbon substrate) [18]. Foam was suppressed by the addition of $0.1 \%$ ergosterol/Tween 80 mixture (consisting of $10 \mathrm{~g} / \mathrm{L}$ ergosterol and $420 \mathrm{~g} / \mathrm{L}$ Tween 80 ) and eight drops of antifoam. Each bioreactor vessel was inoculated with $T$. reesei spores to yield an initial cell density of $1 \times 10^{6}$ spores $/ \mathrm{mL}$. Throughout the fermentation, the temperature was kept at $30^{\circ} \mathrm{C}$, the stirring was kept at $300 \mathrm{rpm}$ and the $\mathrm{pH}$ was kept at 5.5. The fermentation was aborted after 5 days. The protein samples (culture supernatant) were collected by centrifugation for 15 minutes at $12,000 \mathrm{~g}$ and $4^{\circ} \mathrm{C}$.

\section{Protein extraction and 2-DE}

The proteins in the supernatant were precipitated and purified by using a 2-D Clean-Up Kit (GE Healthcare). The purified protein sample was dissolved in rehydration solution (4\% 3-((3-cholamidopropyl) dimethylammonio)-1propanesulfonate (CHAPS), $8 \mathrm{M}$ urea and $0.002 \%$ bromophenol blue) supplemented with 2\% (v/v) 4-7 IPG Buffer (GE Healthcare) and $2.8 \mathrm{mg} / \mathrm{mL}$ dithiothreitol. Regardless of the initial protein concentration in the culture supernatant, the same amount of protein was used for each 2-D gel. Immobiline DryStrip gels $(18 \mathrm{~cm}, \mathrm{pH} 4$ to 7 ; GE Healthcare) were rehydrated overnight at room temperature with $300 \mu \mathrm{g}$ of protein dissolved in rehydration solution (about $400 \mu \mathrm{L}$ ). Isoelectric focusing (IEF) was performed with a Multiphor II system (GE Healthcare) at $20^{\circ} \mathrm{C}$ with a three-phase gradient program: $500 \mathrm{~V}$ for 0.25 $\mathrm{kVh}, 3,500 \mathrm{~V}$ for $5.25 \mathrm{kVh}$ and $3,500 \mathrm{~V}$ for $28 \mathrm{kVh}$. Following IEF, each strip was equilibrated for $12 \mathrm{mi}$ nutes in $10 \mathrm{~mL}$ of SDS equilibration buffer $(50 \mathrm{mM}$ Tris- $\mathrm{HCl}, 6 \mathrm{M}$ urea, 30\% (v/v) glycerol, 2\% (w/v) SDS and $0.002 \%$ bromophenol blue) containing $1 \%(\mathrm{w} / \mathrm{v})$ dithiothreitol. A second equilibration step was then performed with $2.5 \%(\mathrm{w} / \mathrm{v})$ iodoacetamide added to the SDS equilibration buffer. 2-DE was performed on a PROTEAN ${ }^{\mathrm{mm}}$ II electrophoresis system (Bio-Rad, Hercules, CA, USA). The immobilized $\mathrm{pH}$ gradient (IPG) strips were placed on top of $12.5 \%$ polyacrylamide gels and sealed with a solution of $1 \%(\mathrm{w} / \mathrm{v})$ agarose containing a trace of bromophenol blue. The vertical gels were run at $10 \mathrm{~mA}$ per gel for 30 minutes followed by $25 \mathrm{~mA}$ per gel until the bromophenol blue had migrated to the bottom of the gel. The temperature was maintained at $15^{\circ} \mathrm{C}$ using a MultiTemp III system (GE Healthcare). After electrophoresis, the gels were 
stained with SYPRO Ruby Protein Gel Stain (Invitrogen, Carlsbad, CA, USA).

\section{Image analysis}

For comparative analysis, each culture sample was independently prepared and used in 2-DE analyses performed in triplicates. The SYPRO ruby-stained gels were scanned at $532 \mathrm{~nm}$ using a Typhoon 9400 scanner (GE Healthcare). Images were analyzed using ImageMaster II software. After automatic spot detection, artifacts, such as dust on gels, were manually removed and the weaker spots $(<0.1 \%$ of the whole gel volume) were eliminated. The remaining spots were then automatically linked to reference spots on a synthetic reference gel (containing a 1:1 mixture of the protein extract from the two culture supernatants) to allow normalization and comparison of samples. The normalized volume of spots on three replicate 2$\mathrm{D}$ gels was averaged and the standard deviation was calculated.

\section{In-gel digestion and mass spectrometry}

For mass spectrometry analysis, protein spots were picked from the 2-D gels using an Ettan Spot Picker station (GE Healthcare) and distained three times using a fresh solution of $20 \mathrm{mM}$ ammonium bicarbonate containing 35\% (v/v) acetonitrile. Subsequently, the gel pieces were dried by two washes using $100 \%$ neat acetonitrile and rehydrated on ice using a solution of sequencing grade modified trypsin (Promega, Madison, WI, USA) in $20 \mathrm{mM}$ ammonium bicarbonate. The trypsin concentration depended on the intensity of the spots and was 2 to $3 \mathrm{ng} / \mu \mathrm{L}$. The rehydrated gel samples were incubated in $37^{\circ} \mathrm{C}$ for overnight digestion. MALDI-MS spectra for peptides were acquired using a Voyager-DE STR mass spectrometer (AB SIEX, Stockholm, Sweden) as described by Yao et al. [39]. LC-MS/MS combined with ESI-ion-trap MS was performed using an HCTUltra ETD II mass spectrometer from Bruker (Bremen, Germany) linked to an Easy-nLC system from Proxeon (Odense, Denmark). Spectra were acquired using the enhanced scanning mode covering a mass range from $\mathrm{m} / \mathrm{z} 300$ to $\mathrm{m} / \mathrm{z} 1,300$. The LC separation of peptides was performed using a $5 \mu \mathrm{m}$ C18 column $(375 \mu \mathrm{m}$ OD/ $75 \mu \mathrm{m} \mathrm{ID} \times 10 \mathrm{~cm}$ ) from NanoSeparations (Nieuwkoop, The Netherlands) and a 30-minute gradient ranging from 0 to $60 \%$ of acetonitrile. The flow rate was $300 \mathrm{~nL} /$ $\mathrm{min}^{-1}$. Database searches using the peak list files of the processed mass spectra were performed using an inhouse license of Mascot (Matrix Science Inc., Boston, MA, USA; www.matrixscience.com) and the Genome Portal of the Department of Energy Joint Genome Institute (JGI, Walnut Creek, CA, USA; www.jgi.doe.gov) for T. reesei.

\section{Enzymatic assays}

Enzymatic activities were measured in culture supernatants obtained after centrifugation. Overall cellulase activity of the samples was determined as FPase using Whatman No. 1 filter paper strips as the substrate [40]. Endoglucanase activity was measured as CMCase with carboxymethyl cellulose (CMC) dissolved in $50 \mathrm{mM}$ citrate buffer ( $\mathrm{pH}$ 5.0) as the substrate. The assay was performed for 30 minutes at $50^{\circ} \mathrm{C}$. Xylanase activity was assayed by the method described by Bailey et al. [41]. Oat spelt xylan (Sigma-Aldrich, St Louis, MO, USA) was used as the substrate. The amount of released sugar was assayed via the dinitrosalicylic acid (DNS) method using glucose or xylose as the standard [42]. $\beta$-Glucosidase activities were determined using 4-nitrophenyl- $\beta$-D-glucopyranoside with para-nitrophenol as the standard [43]. One unit (U) of enzyme activity was defined as the quantity of enzyme that liberated substrate at the rate of $1 \mu \mathrm{mol}$ per minute.

\section{Biomass and chemical analysis}

To determine the microbial biomass production (cell dry weight), the $T$. reesei cells were harvested continuously through filtration. Harvested cells were washed and dried at $80^{\circ} \mathrm{C}$ until constant weight was achieved. The monosaccharide content in the CMM and LCM after fermentation was analyzed by anion exchange chromatography using a DX-500 system (Dionex, Sunnyvale, CA, USA) equipped with a CarboPac PA1 column (Dionex) [44].

\section{Abbreviations \\ 2-DE: Two-dimensional gel electrophoresis; ABFl: Arabinofuranosidase; BGLI: $\beta$-Glucosidase I; Cel5a: Endoglucanase II; Cel6a: Cellobiohydrolase II; Cel7a: Cellobiohydrolase I; Cel7b: Endoglucanase I; Cel12a: Endoglucanase III; Cel61a: Endoglucanase IV; Cel74a: Xyloglucanase; CHAPS: 3-((3- cholamidopropyl) dimethylammonio)-1-propanesulfonate; CIPI: Cellulose- binding protein; CMC: Carboxymethyl cellulose; CMCase: Activity on carboxymethyl cellulose; CMM: Cane molasses medium; DNS: Dinitrosalicylic acid; ESI-LC MS/MS: Electrospray ionization liquid chromatography tandem mass spectrometry; FPase: Filter paper activity; IEF: Isoelectric focusing; IPG: Immobilized pH gradient; JGI: Joint Genome Institute; LCM: Lactose- based conventional medium; MALDI-MS: Matrix-assisted laser desorption/ ionization mass spectrometry; MANI: Mannanase l; pl: Isoelectric point; XYN: Xylanase; XYNI: Xylanase I; XYNIV: Xylanase IV.}

\section{Competing interests}

The authors declare that they have no competing interests.

\section{Authors' contributions}

$\mathrm{HJ}$ and MX carried out the sample preparation and the 2-DE analyses. WA, $Y J$ and TG carried out in-gel digestions and chemical analyses. CD, YB and ZP performed the mass spectrometric analyses and database searches. All authors substantially contributed to the analysis and the drafting of the manuscript. All authors read and approved the final manuscript.

\section{Acknowledgements}

This work was supported by the 'Prominent Young Scientist Fund' of Sichuan Province (2013JQ0039) and the Program for Changjiang Scholars and Innovative Research Team in University (IRT13083). 


\section{Author details}

${ }^{1}$ Institute of Animal Nutrition, Sichuan Agricultural University, Ya'an, Sichuan 625014, People's Republic of China. ${ }^{2}$ College of Forestry, South China Agricultural University, Guangzhou 510642, People's Republic of China.

Received: 20 October 2013 Accepted: 11 March 2014

Published: 24 March 2014

\section{References}

1. Sun $Y$, Cheng J: Hydrolysis of lignocellulosic materials for ethanol production: a review. Bioresour Technol 2002, 83:1-11.

2. Farrell AE, Plevin RJ, Turner BT, Jones AD, O'Hare M, Kammen DM: Ethanol can contribute to energy and environmental goals. Science 2006 , 311:506-508.

3. Patel-Predd P: Overcoming the hurdles to producing ethanol from cellulose. Environ Sci Technol 2006, 40:4052-4053.

4. Martinez D, Berka RM, Henrissat B, Saloheimo M, Arvas M, Baker SE, Chapman J, Chertkov O, Coutinho PM, Cullen D, Danchin EGJ, Grigoriev IV, Harris $\mathrm{P}$, Jackson $\mathrm{M}$, Kubicek $\mathrm{CP}$, Han CS, Ho I, Larrondo LF, de Leon AL, Magnuson JK, Merino S, Misra M, Nelson B, Putnam N, Robbertse B, Salamov AA, Schmoll M, Terry A, Thayer N, Westerholm-Parvinen A, et al: Genome sequencing and analysis of the biomass-degrading fungus Trichoderma reesei (syn. Hypocrea jecorina). Nat Biotechnol 2008, 26:553-560.

5. Cherry JR, Fidantsef AL: Directed evolution of industrial enzymes: an update. Curr Opin Biotechnol 2003, 14:438-443.

6. Gritzali M Jr, Brown RD: The cellulase system of Trichoderma. The relationship between purified extracellular enzymes from induced or cellulose grown cells. Adv Chem Ser 1979, 181:237-260.

7. Allen $A L$, Roche $C D$ : Effects of strain and fermentation conditions on production of cellulase by Trichoderma reesei. Biotechnol Bioeng 1989, 33:650-656.

8. Nakari-Setala T, Penttila M: Production of Trichoderma reesei cellulases on glucose-containing media. Appl Environ Microbiol 1995, 61:3650-3655

9. Chaudhuri BK, Sahai V: Production of cellulase using a mutant strain of Trichoderma reesei growing on lactose in batch cultures. Appl Microbiol Biotechnol 1993, 39:194-196.

10. Jun $\mathrm{H}$, Kieselbach $\mathrm{T}$, Jonsson $\amalg$ : Enzyme production by filamentous fungi: analysis of the secretome of Trichoderma reesei grown on unconventional carbon source. Microbial Cell Fact 2011, 10:68.

11. Xin L, Jibin S, Nimtz M, Wissing J, An-Ping Z, Rinas U: The intra- and extracellular proteome of Aspergillus niger growing on defined medium with xylose or maltose as carbon substrate. Microbial Cell Fact 2010, 9:23

12. Jiang L, Wang J, Liang S, Wang X, Cen P, Xun Z: Butyric acid fermentation in a fibrous bed bioreactor with immobilized Clostridium tyrobutyricum from cane molasses. Bioresour Technol 2009, 100:3403-3409.

13. Liu YP, Zhen P, Sun ZH, Ni Y, Dong JJ, Zhu LL: Economical succinic acid production from cane molasses by Actinobacillus succinogenes. Bioresour Technol 2008, 99:1736-1742.

14. Ling $M$, Chen GG, Lin YS, Liang ZQ: Induction of cellulase gene transcription by a novel oligosaccharide: molasses alcohol stillage substance. World J Microbiol Biotechnol 2009, 25:1485-1489.

15. Singh B, Satyanarayana T: Phytase production by Sporotrichum thermophile in a cost-effective cane molasses medium in submerged fermentation and its application in bread. J Appl Microbiol 2008, 105:1858-1865

16. Ilmen $\mathrm{M}$, Thrane $\mathrm{C}$, Penttila $\mathrm{M}$ : The glucose repressor gene cre1 of Trichoderma: isolation and expression of a full-length and a truncated mutant form. Mol Gene Genet 1996, 251:451-460.

17. Ilmen M, Saloheimo A, Onnela ML, Penttila M: Regulation of cellulase gene expression in the filamentous fungus Trichoderma reesei. Applied Environ Microbiol 1997, 63:1298-1306.

18. Juhasz T, Szengyel Z, Reczey K, Siika-Aho M, Viikari L: Characterization of cellulases and hemicellulases produced by Trichoderma reesei on various carbon sources. Process Biochem 2005, 40:3519-3525

19. Foreman PK, Brown D, Dankmeyer L, Dean R, Diener S, Dunn-Coleman NS, Goedegebuur F, Houfek TD, England GJ, Kelly AS, Meerman HJ, Mitchell T, Mitchinson C, Olivares HA, Teunissen PJ, Yao L, Ward M: Transcriptional regulation of biomass-degrading enzymes in the filamentous fungus Trichoderma reesei. J Biol Chem 2003, 278:31988-31997.

20. Stricker $A R$, Mach $R L$, de Graaff $L H$ : Regulation of transcription of cellulase- and hemicellulase-encoding genes in Aspergillus niger and Hypocrea jecorina (Trichoderma reesei). Appl Microbiol Biotechnol 2008, 78:211-220

21. Purkarthofer $H$, Steiner $W$ : Induction of endo- $\beta$-xylanase in the fungus Thermomyces lanuginosus. Enzyme Microb Technol 1995, 7:114-118.

22. Morikawa Y, Ohashi T, Mantani O, Okada H: Cellulase induction by lactose in Trichoderma reesei PC-3-7. Appl Microbiol Biotechnol 1995 44:106-111.

23. Xiong $\mathrm{H}$, Turunen $\mathrm{O}$, Pastinen $\mathrm{O}$, Leisola $\mathrm{M}$, von Weymarn $\mathrm{N}$ : Improved xylanase production by Trichoderma reesei grown on L-arabinose and lactose or D-glucose mixtures. Appl Microbiol Biotechnol 2004, 64:353-358

24. Sandgren M, Stahlberg J, Mitchinson C: Structural and biochemical studies of GH family 12 cellulases: improved thermal stability, and ligand complexes. Prog Biophys Mol Biol 2005, 89:246-291.

25. Miettinen-Oinonen A, Paloheimo M, Lantto R, Suominen P: Enhanced production of cellobiohydrolases in Trichoderma reesei and evaluation of the new preparations in biofinishing of cotton. J Biotechnol 2005, 116:305-317.

26. Herpoel-Gimbert I, Margeot A, Dolla A, Jan G, Molle D, Lignon S, Mathis H, Sigoillot JC, Monot F, Asther M: Comparative secretome analyses of two Trichoderma reesei RUT-C30 and CL847 hypersecretory strains. Biotechnol Biofuel 2008, 1:18.

27. Shallom D, Shoham Y: Microbial hemicellulases. Curr Opin Microbiol 2003, 6:219-223.

28. Torronen A, Mach RL, Messner R, Gonzalez R, Kalkkinen N, Harkki A, Kubicek CP: The two major xylanases from Trichoderma reesei: characterization of both enzymes and genes. Biogeosciences 1992, 10:1461-1465

29. Seiboth B, Hartl L, Salovuori N, Lanthaler K, Robson GD, Vehmaanperä J, Penttilä ME, Kubicek CP: Role of the bga1-encoded extracellular $\beta$-galactosidase of Hypocrea jecorina in cellulase induction by lactose. Appl Environ Microbiol 2005, 71:851-857.

30. Ouyang J, Yan M, Kong D, Xu L: A complete protein pattern of cellulose and hemicellulase genes in the filamentous fungus Trichoderma reesei. Biotechnol J 2006, 1:1266-1274.

31. Karlsson J, Siika-aho M, Tenkanen M, Tjerneld F: Enzymatic properties of the low molecular mass endoglucanases Cel12A (EGIII) and Cel45A (EGV) of Trichoderma reesei. J Biotechnol 2002, 99:63-78.

32. Komili S, Silver PA: Coupling and coordination in gene expression processes: a systems biology view. Nat Rev Genet 2008, 9:38-48.

33. Strauss J, Kubicek CP: $\beta$-Glucosidase and cellulase formation by a Trichoderma reesei mutant defective in constitutive $\beta$-glucosidase formation. J Gen Microbiol 1990, 136:1321-1326.

34. Sternberg D, Mandels GR: Regulation of the cellulolytic system of Trichoderma reesei by sophorose: induction of cellulase and repression of B-glucosidase. J Bacteriol 1980, 144:1197-1199.

35. Fowler T, Brown RD Jr: The bgl1 gene encoding extracellular $\beta$-glucosidase from Trichoderma reesei is required for rapid induction of the cellulase complex. Mol Microbiol 1992, 6:3225-3235.

36. Rajoka Ml: Regulation of synthesis of endo-xylanse and $\beta$-xylosidase in Cellulomonas flavigena: a kinetic study. World J Microb Biotechnol 2005, 21:463-469.

37. Rajoka Ml: Kinetic parameters and thermodynamic values of $\beta$-xylosidase production by Klyyveromyces marxianus. Bioresour Technol 2007, 98:2212-2219.

38. Roukas T: Pretreatment of beet molasses to increase pullulan production. Process Biochem 1998, 33:805-810.

39. Yao D, Kieselbach T, Komenda J, Promnares K, Prieto MA, Tichy M, Vermaas W, Funk C: Localization of the small CAB-like proteins in photosystem II. J Biol Chem 2007, 282:267-276.

40. Ghose TK: Measurement of cellulase activities. Pure App/ Chem 1987, 59:257-268.

41. Bailey MJ, Biely P, Poutanen K: Interlaboratory testing of methods for assay of xylanase activity. J Biotechnol 1992, 23:257-270.

42. Miller GL, Blum R, Glennon WE, Burton AL: Measurement of carboxymethylcellulase activity. Anal Biochem 1960, 2:127-132. 
43. Berghem LER, Petterson LG: The mechanism of enzymatic cellulose degradation: Isolation and some properties of $\beta$-glucosidase form Trichderma viride. Eur J Biochem 1974, 46:295-305.

44. Alriksson B, Rose SH, Van Zyl WH, Sjöde A, Nilvebrant N-O, Jönsson LJ: Cellulase production from spent lignocelluloses hydrolysates by recombinant Aspergillus niger. Appl Environ Microbiol 2009, 75:2366-2374

doi:10.1186/1754-6834-7-43

Cite this article as: He et al.: Cost-effective lignocellulolytic enzyme production by Trichoderma reesei on a cane molasses medium. Biotechnology for Biofuels 2014 7:43.

\section{Submit your next manuscript to BioMed Central and take full advantage of:}

- Convenient online submission

- Thorough peer review

- No space constraints or color figure charges

- Immediate publication on acceptance

- Inclusion in PubMed, CAS, Scopus and Google Scholar

- Research which is freely available for redistribution 